\title{
Transcriptional Coactivator YAP1
}

National Cancer Institute

\section{Source}

National Cancer Institute. Transcriptional Coactivator YAP1. NCI Thesaurus. Code C96032.

Transcriptional coactivator YAP1 (504 aa, $\sim 54 \mathrm{kDa}$ ) is encoded by the human YAP1 gene.

This protein plays a role in the modulation of both signaling pathways and gene expression. 